University of Wollongong

Research Online

Faculty of Engineering and Information

Faculty of Engineering and Information

Sciences - Papers: Part B

Sciences

2019

Mechanical properties of steel, glass, and hybrid fiber reinforced reactive powder concrete

Atheer Hilal Mahdi Al - Gburi

University of Wollongong, ahmag930@uowmail.edu.au

M Neaz Sheikh

University of Wollongong, msheikh@uow.edu.au

Muhammad N. S Hadi

University of Wollongong, mhadi@uow.edu.au

Follow this and additional works at: https://ro.uow.edu.au/eispapers1

Part of the Engineering Commons, and the Science and Technology Studies Commons

Research Online is the open access institutional repository for the University of Wollongong. For further information contact the UOW Library: research-pubs@uow.edu.au 


\title{
Mechanical properties of steel, glass, and hybrid fiber reinforced reactive powder concrete
}

\author{
Abstract \\ This study examines the properties of fiber-reinforced reactive powder concrete (FR-RPC). Steel fibers, \\ glass fibers, and steel-glass hybrid fibers were used to prepare the FR-RPC. The non-fibrous reactive \\ powder concrete (NF-RPC) was prepared as a reference mix. The proportion of fibers by volume for all FR- \\ RPC mixes was $1.5 \%$. Steel fibers of $13 \mathrm{~mm}$ length and $0.2 \mathrm{~mm}$ diameter were used to prepare the steel \\ fiber-reinforced RPC (SFR-RPC). Glass fibers of $13 \mathrm{~mm}$ length and $1.3 \mathrm{~mm}$ diameter were used to prepare \\ the glass fiber-reinforced RPC (GFR-RPC). The hybrid fiber-reinforced RPC (HFR-RPC) was prepared by \\ mixing $0.9 \%$ steel fibers and $0.6 \%$ glass fibers. Compressive strength, axial load-axial deformation \\ behavior, modulus of elasticity, indirect tensile strength, and shear strength of the RPC mixes were \\ investigated. The results showed that SFR-RPC achieved higher compressive strength, indirect tensile \\ strength and shear strength than NF-RPC, GFR-RPC, and HFR-RPC. Although the compressive strengths of \\ GFR-RPC and HFR-RPC were slightly lower than the compressive strength of NF-RPC, the shear strengths \\ of GFR-RPC and HFR-RPC were higher than that of NF-RPC.

\section{Disciplines} \\ Engineering | Science and Technology Studies

\section{Publication Details} \\ Algburi, A. H. M., Sheikh, M. Neaz. \& Hadi, M. N. S. (2019). Mechanical properties of steel, glass, and \\ hybrid fiber reinforced reactive powder concrete. Frontiers of Structural and Civil Engineering, 13 (4), \\ 998-1006.
}




\section{Mechanical Properties of Steel, Glass and Hybrid Fibre Reinforced Reactive}

(1)

\section{Powder Concrete}

${ }^{1}$ Ph.D. Candidate, School of Civil, Mining and Environmental Engineering, University of Wollongong, NSW 2522, Australia. E-mail: ahmag930@uowmail.edu.au

M. Neaz Sheikh ${ }^{2}$

${ }^{2}$ Associate Professor, School of Civil, Mining and Environmental Engineering, University of Wollongong, NSW 2522, Australia. E-mail: msheikh@uow.edu.au

Muhammad N.S. Hadi ${ }^{3 *}$

${ }^{3}$ Associate Professor, School of Civil, Mining and Environmental Engineering, University of Wollongong, NSW 2522, Australia, ${ }^{*}$ Corresponding Author, Email: mhadi@uow.edu.au. Tel.: +61 24221 4762; Fax: +61242213238.

\section{Abstract}

This study examines the properties of fibre-reinforced reactive powder concrete (FR-RPC). Steel fibres, glass fibres and steel-glass hybrid fibres were used to prepare the FR-RPC. The non-fibrous RPC (NF-RPC) was prepared as a reference mix. The proportion of fibres by volume for all FRRPC mixes was $1.5 \%$. Steel fibres of $13 \mathrm{~mm}$ length and $0.2 \mathrm{~mm}$ diameter were used to prepare the steel fibre-reinforced RPC (SFR-RPC). Glass fibres of $13 \mathrm{~mm}$ length and $1.3 \mathrm{~mm}$ diameter were used to prepare the glass fibre-reinforced RPC (GFR-RPC). The hybrid fibre-reinforced RPC (HFR-RPC) was prepared by mixing $0.9 \%$ steel fibres and $0.6 \%$ glass fibres. Compressive strength, axial load-axial deformation behaviour, modulus of elasticity, indirect tensile strength, 
24 and shear strength of the RPC mixes were investigated. The results showed that SFR-RPC

25 achieved higher compressive strength, indirect tensile strength and shear strength than NF-RPC,

26 GFR-RPC and HFR-RPC. Although the compressive strengths of GFR-RPC and HFR-RPC were

27 slightly lower than the compressive strength of NF-RPC, the shear strengths of GFR-RPC and

28 HFR-RPC were higher than that of NF-RPC.

KEYWORDS: Reactive powder concrete, steel fibre, glass fibre, hybrid fibre.

\section{Introduction}

32 Reactive powder concrete (RPC) is a special type of high performance concrete (HPC), which was

33 introduced by Richard and Cheyrezy [1] in France in 1995. The dense structure of RPC is formed

34 mainly by cement, silica fume, fine aggregate, water, and superplasticiser with the absence of the

35 coarse aggregate. The RPC possesses superior mechanical and durability properties compared to

36 other types of HPC. Nevertheless, like high strength concrete, RPC is susceptible to brittle failure.

37 One of the methods to increase the ductility of the RPC is the addition of fibres. Steel fibres have

38 long been used for this purpose [2-5].

40 Richard and Cheyrezy [1] prepared RPC with a compressive strength of $200 \mathrm{MPa}$. Over the last

41 two decades, however, many researchers prepared the RPC by using the available materials with

42 different mix components and curing methods. The prepared RPC cured by using standard curing

43 conditions (water tank with a temperature range of $20-25{ }^{\circ} \mathrm{C}$ ) achieved compressive strength

44 ranging between $84 \mathrm{MPa}$ to $212 \mathrm{MPa}$ [4, 6-9]. Liu and Huang [10] prepared highly flowable RPC

45 cured under autoclave technique, which achieved only $75 \mathrm{MPa}$. The low compressive strength of 
46 the RPC prepared by Liu and Huang [10] can be attributed to the high flowability of the RPC.

47 Ahmed et al. [11] also found that increasing the flowability of the RPC by increasing the dosage

48 of superplasticiser and decreasing the grading of the sand decreased the compressive strength of

49 the RPC [11].

51 Richard and Cheyrezy [1] recommended using steel fibres of $2 \%$ by volume in the RPC. The

52 influence of the volume fraction of the steel fibres on the compressive strength of the RPC varies

53 depending on the type of the steel fibres. Al-Tikrite and Hadi [9] revealed that the compressive

54 strength of RPC increased by increasing proportion of micro steel fibres from 1\% to 4\% by volume.

55 However, Al-Tikrite and Hadi [9] also found that increasing proportion of deformed steel fibres

56 from $1 \%$ to $4 \%$ by volume had a marginal effect on the compressive strength of the RPC [9].

57 Yunsheng et al. [3] prepared RPC using 0\%, 2\%, 3\%, and 4\% of steel fibres (13 mm long with

58 diameter $0.175 \mathrm{~mm}$ ) by volume. The results demonstrated that the RPC with $4 \%$ of steel fibres by

59 volume achieved higher compressive strength than RPC with 0\%, 2\% and 3\% steel fibres by

60 volume. Ju et al. [12] reported that the RPC mix with 1.5\% steel fibres (13 mm long with diameter

$610.2 \mathrm{~mm}$ ) by volume achieved higher compressive strength and tensile strength than the RPC mix

62 with $0 \%$ and $1 \%$ steel fibres (13 $\mathrm{mm}$ long with diameter $0.2 \mathrm{~mm}$ ) by volume.

63

64 Recently, Al-Tikrite and Hadi [9] investigated the influence of micro steel fibres, industrial

65 deformed steel fibres and waste steel fibres on the mechanical properties of RPC. The results

66 showed that micro steel fibre reinforced RPC achieved higher strength than the RPC with industrial

67 and waste steel fibres. Also, the RPC with waste steel fibres achieved higher strength and ductility 
68 than non-fibrous reactive powder concrete (NF-RPC) and achieved comparable strength and

69 ductility to the RPC with industrial steel fibres.

71 It was found from an extensive literature review that only a few studies investigated the effect of

72 replacing the steel fibres by the other types of fibres in the RPC, especially to enhance the

73 durability of the RPC in aggressive environments. For instance, Shaheen and Shrive [13] used

74 carbon fibres ( $3 \mathrm{~mm}$ long with a fibre to cement ratio of 0.125 by weight) to produce more durable

75 RPC against freezing and thawing than steel fibre reinforced RPC (SFR-RPC). It was found that

76 carbon fibre reinforced RPC and SFR-RPC (12 mm long steel fibres with a fibre to cement ratio

77 of 0.2 by weight) achieved comparable durability against freezing and thawing. Also, carbon fibre

78 reinforced RPC achieved significantly higher compressive strength, tensile strength and fracture

79 toughness than NF-RPC. Sanchayan and Foster [14] used 2\% by volume of hybrid steel-polyvinyl

80 alcohol (PVA) fibres to alleviate the explosive behaviour of the RPC at high temperature. The test

81 results revealed that RPC with 1\% PVA by volume plus 1\% steel fibres by volume (50\% steel

82 fibres) achieved higher compressive strength than the RPC with hybrid fibres containing 25\% or

$8375 \%$ steel fibres by volume plus the remaining percentage of PVA fibres (total 2\% by volume of

84 hybrid fibres). Also, Canbaz [15] reported that RPC with $1 \%$ by volume of polypropylene fibres

85 achieved higher compressive strength than the RPC containing $0.5 \%$ and $1.5 \%$ polypropylene

86 fibres by volume before and after the exposure to high temperature.

87

88 Cement mortar with glass fibre (called glass fibre reinforced concrete, GFRC) has been used in

89 many architectural applications. In addition, the premix of GFRC has been used in some structural

90 members with compressive strengths ranging between $40 \mathrm{MPa}$ and $60 \mathrm{MPa}$ [16]. The GFRC has 
91 also been used in other civil engineering applications, which include construction of permanent

92 formwork, lining of sewer trunk line, bulky headwall, storage structures, and roofs [17].

93 Considering the excellent corrosion resistance and the low self-weight of glass fibres, the inclusion

94 of glass fibres and steel-glass hybrid fibres in the RPC needs to be investigated.

95

96 This study investigates the compressive strength, axial load-axial deformation behaviour, modulus

97 of elasticity, indirect tensile strength and shear strength of RPC containing $1.5 \%$ by volume of

98 three different types of fibres: steel, glass, and hybrid steel-glass fibres.

\section{2. Experimental program}

$100 \quad 2.1$ Materials

101 General purpose (Type GP) cement according to AS 3972-2010 [18] was used for all mixes of 102 non-fibrous reactive powder concrete (NF-RPC) and fibre-reinforced reactive powder concrete 103 (FR-RPC). Densified silica fume was used as a supplementary cementitious material. This form 104 of amorphous silica is a condensed silica fume manufactured by the SIMCOA silicon plant in 105 Western Australia [19] and was supplied by the Australasian (iron \& steel) Slag Association [20].

106 Washed fine river sand with particles size between $0.15 \mathrm{~mm}$ and $0.6 \mathrm{~mm}$ and fineness modulus of 1071 was used to prepare all the RPC mixes. The superplasticiser used in this study was Sika viscocrete 108 PC HRF-2 [21]. Tap water was used in all the RPC mixes. Steel fibres, glass fibres and hybrid 109 steel-glass fibres were used in this study. The steel fibres were $13 \mathrm{~mm}$ long and had $0.2 \mathrm{~mm}$ 110 diameter with a nominal tensile strength of $2500 \mathrm{MPa}$. Steel fibres were supplied by Steel Wire 111 Fibre in China [22]. The glass fibres were high integrity alkali resistant glass (ARG) fibres, which 112 were $13 \mathrm{~mm}$ long and had $1.3 \mathrm{~mm}$ diameter with a nominal tensile strength of $1500 \mathrm{MPa}$ [23]. 113 Glass fibres were produced by NEG, Japan [23]. In this study, FR-RPC was prepared by adding 
$114 \quad 1.5 \%$ fibres by volume. The hybrid fibres were a mix of $0.9 \%$ steel fibres and $0.6 \%$ glass fibres by

115 volume. Steel and glass fibres used in this study are shown in Fig. 1. The properties of the steel 116 and glass fibres are listed in Table 1.

$118 \quad 2.2$ Mix proportioning and casting

119 Four RPC mixes were prepared based on the mix proportion suggested in Richard and Cheyrezy 120 [1]. However, some modifications were carried out due to the use of local materials and the 121 addition of fibres. The mix design of NF-RPC consisted of $880 \mathrm{~kg} / \mathrm{m}^{3}$ cement, $220 \mathrm{~kg} / \mathrm{m}^{3}$ silica 122 fume, $924 \mathrm{~kg} / \mathrm{m}^{3}$ fine sand, $48.4 \mathrm{l} / \mathrm{m}^{3}$ superplasticiser and $158.4 \mathrm{~kg} / \mathrm{m}^{3}$ water. The steel fibre 123 reinforced reactive powder concrete (SFR-RPC), glass fibre reinforced reactive powder concrete 124 (GFR-RPC), and hybrid-fibre reinforced reactive powder concrete (HFR-RPC) were prepared by 125 adding $1.5 \%$ steel fibres, $1.5 \%$ glass fibres and $1.5 \%$ hybrid fibres $(0.9 \%$ of steel fibre plus $0.6 \%$ 126 of glass fibre) by volume, respectively. The combination of $0.9 \%$ steel fibre and $0.6 \%$ glass fibre

127 was used, based on a preliminary study by the authors. The proportion of fibres (1.5\%) was 128 selected based on the experimental study in Ju et al. [12]. A small amount of the superplasticiser 129 and water were added to SFR-RPC, GFR-RPC and HFR-RPC mixes in order to keep the 130 workability close to the workability of the reference mix (NF-RPC). The water content and 131 superplasticiser dosage for the FR-RPC mixes was $163.7 \mathrm{~kg} / \mathrm{m} 3$ and $52.8 \mathrm{l} / \mathrm{m} 3$, respectively.

133 The RPC batches were mixed using a vertical pan mixer at 15 revolutions per minute. The pan 134 mixer was charged with the dry materials. The mixer was operated for about 5 minutes to maintain 135 uniformity of the dry materials. Afterwards, water mixed with superplasticiser was added 136 gradually. First, about two-thirds of the fluid (water mixed with superplasticiser) was added and 
137 mixed for about four minutes then the rest of the fluid was added. The average total mixing time

138 for the NF-RPC mix was about 18 minutes. The addition of the fibres was the last step in the

139 mixing process. The fibres were added to the mix by using a $16 \mathrm{~mm}$ sieve fixed on the mixer mesh

140 cover during the mixing operation. No balling was observed during the addition and mixing of

141 both steel and glass fibres. In total, the average mixing time was about 23 minutes for the FR-RPC.

142 Workability of NF-RPC and FR-RPC mixes was examined by applying flow table test according 143 to ASTM C230/C230M-14 [24] (Fig. 2). The ASTM C230/C230M-14 [24] was also used to test

144 the workability in Al-Tikrite and Hadi [9] and Malik and Foster [25]. The test was conducted

145 before casting the specimens. Only 15 drops were performed and the average flow diameter of the

146 RPC mixes was measured. The 15 drops achieved a reasonable average flow diameter $(200 \mathrm{~mm})$

147 for the NF-RPC. Therefore, the 15 drops were taken as a reference. The average flow diameters

148 for the SFR-RPC, GFR-RPC and HFR-RPC were $190 \mathrm{~mm}, 180 \mathrm{~mm}$ and $185 \mathrm{~mm}$, respectively, as

149 presented in Table 2.

150

151 The RPC specimens were cast and compacted in layers inside the moulds according to the 152 recommendations of the standards [26-29]. The test specimens were compacted using a table

153 vibrator. Next, the specimens were covered with plastic sheets until the demoulding of the 154 specimens on the following day. Finally, the specimens were cured in a water tank with a 155 temperature range of $20-25^{\circ} \mathrm{C}$.

156

$157 \quad 2.3$ Test matrix

158 Three specimens each were tested to determine the properties investigated in this study. Two 159 different standard cylinder specimens were used: $100 \mathrm{~mm} \times 200 \mathrm{~mm}$ cylinder specimens for the 
160 compressive strength test and $150 \mathrm{~mm} \times 300 \mathrm{~mm}$ cylinder specimens for the modulus of elasticity

161 and the splitting tensile strength tests. Also, $100 \mathrm{~mm} \times 100 \mathrm{~mm} \times 500 \mathrm{~mm}$ prism specimens were

162 used for the shear strength test. All tests were carried out at 28 days except the compressive

163 strength test of the NF-RPC which was carried out at 7, 28 and 56 days to determine the gain in

164 the compressive strength.

165

$166 \quad 2.4$ Test method of compressive strength

167 The compressive strength of all the specimens was determined according to AS 1012.9-2014 [26].

168 A standard compression machine with a capacity of $1800 \mathrm{kN}$ was used for the compressive strength

169 test.

170

1712.5 Test method of axial load-axial deformation behaviour and modulus of elasticity

172 The axial load-axial deformation behaviour and modulus of elasticity of the RPC mixes were

173 investigated. The test was conducted according to AS 1012.17-2014 [27] by using a Denison

174 compression machine with a capacity of $5000 \mathrm{kN}$. The test was performed with $150 \mathrm{~mm} \times 300$

175 mm cylinder specimens. The specimens were capped with high strength plaster and tested after

176 two hours of removing from the curing tank. A standard compressometer with a linear variable

177 differential transducer (LVDT) was used to measure the axial deformation. The compressometer

178 was positioned symmetrically at the mid-height of the specimen, as shown in Fig. 3. The length

179 over which the axial deformation was measured was $114 \mathrm{~mm}$. The axial load was obtained directly

180 from the test machine. The test was performed under a displacement-control loading of $0.3 \mathrm{~mm}$

181 per minute. The data were acquired through a Data Acquisition System. The modulus of elasticity

182 was determined using Eq. (1): 


$$
E=\frac{G_{2}-G_{1}}{\varepsilon_{2}-0.00005}
$$

184 where $E=$ modulus of elasticity (MPa), $G_{2}=$ stress that equals to $40 \%$ of the average compressive 185 strength (MPa), $G_{1}=$ stress at 0.00005 axial strain $(\mathrm{MPa})$ and $\varepsilon_{2}=$ axial strain at $G_{2}(\mathrm{~mm} / \mathrm{mm})$. 186

$187 \quad 2.6$ Test method of indirect tensile strength

188 Indirect tensile strength of the RPC was determined by the Brazilian test according to AS 1012.101892014 [28]. Cylinder specimens of $150 \mathrm{~mm} \times 300 \mathrm{~mm}$ were used to perform the test. A compression 190 machine with a capacity of $1800 \mathrm{kN}$ was used to perform the indirect tensile strength test (Fig. 4). 191 Splitting tensile strength was determined by using Eq. (2).

192

$$
T=\frac{2000 P}{\pi D L}
$$

194 where $T=$ splitting tensile strength $(\mathrm{MPa}), P=$ maximum applied load $(\mathrm{kN}), D=$ diameter of 195 specimen $(\mathrm{mm}), L=$ length of specimen $(\mathrm{mm})$ and $\pi=3.14$.

$197 \quad 2.7$ Test method of direct shear strength

198 Shear strength test for NF-RPC and FR-RPC was conducted according to JSCE SF6-1999 [29] 199 Prism specimens with dimensions of $100 \mathrm{~mm} \times 100 \mathrm{~mm} \times 500 \mathrm{~mm}$ were used to perform the test. 200 The test was conducted with some modifications to create stress concentration. Two notches were 201 created around the entire test specimen (Figure 5). The notches were created on the hardened 202 specimens by using an electric saw. Each notch had a depth of $10 \mathrm{~mm}$ and a width of $2.5 \mathrm{~mm}$. The 
203 load was applied by using two steel loading edges. The out-to-out distance between the steel

204 loading edges was the same of the clear distance between the notches $(100 \mathrm{~mm})$. The specimen

205 was supported by two rigid steel blocks. The clear distance between the rigid steel blocks was 105

$206 \mathrm{~mm}$. The schematic diagram of the test setup is shown in Fig. 5. A standard hydraulic machine

207 with a capacity of $300 \mathrm{kN}$ was used for the test. The test setup of the direct shear test is shown in

208 Fig. 6.

\section{3. Results and discussion}

2103.1 Compressive strength of NF-RPC and FR-RPC

211 Figure 7 shows age versus compressive strength for NF-RPC. The average compressive strength

212 of NF-RPC at 28 days was $90 \mathrm{MPa}$ and the ratio of the 7-day compressive strength to the 28-day

213 compressive strength was $88 \%$. It is noted that the ratio of the compressive strength at 7 days to

214 the compressive strength at 28 days of NF-RPC is higher than that of normal strength concrete,

215 which is usually about $66 \%$ [30]. Hence, the ratio of the compressive strength at 7 days to the

216 compressive strength at 28 days for the RPC is higher than that of the normal strength concrete by

217 about 33\%. This indicates that RPC can be a suitable option for concrete structural members that

218 need high early compressive strengths such as columns on the ground floor of high-rise buildings

219 and footbridges. However, the ratio of the 56-day compressive strength to the 28-day compressive

220 strength of NF-RPC was about $113 \%$, which is the same as the ratio of the 56-day compressive

221 strength to the 28-day compressive strength for the normal strength concrete [30].

223 As reported in above, the average compressive strength of NF-RPC was $90 \mathrm{MPa}$ at 28 days which

224 can be considered relatively low for the RPC. The low compressive strength of NF-RPC can be

225 attributed to the high dosage of the superplasticiser that increased the air content in the RPC matrix 
226 and led to inadequate compaction. The other possible reason for the relatively low compressive 227 strength of NF-RPC was the relatively high flowability of the NF-RPC (the average flow diameter 228 of NF-RPC was $200 \mathrm{~mm}$ ). The average compressive strength of SFR-RPC was $96 \mathrm{MPa}$. The 229 increase in the compressive strength of SFR-RPC compared to the compressive strength of NF230 RPC was due to the addition of steel fibres. The presence of the discrete steel fibres in the SFR231 RPC matrix decreased the lateral tensile stresses and increased energy absorption capacity of SFR232 RPC and led to an increase in the compressive strength [5]. Similar findings were also reported in 233 Ju et al. [12]. Ju et al. [12] reported that SFR-RPC containing 1.5\% steel fibres by volume achieved 234 higher compressive strength than NF-RPC. In contrast, the average compressive strengths of GFR235 RPC and HFR-RPC were $81 \mathrm{MPa}$ and $85 \mathrm{MPa}$, respectively, as presented in Table 2. The lower 236 compressive strength for GFR-RPC compared to that of NF-RPC was probably due to the high 237 aspect ratio of the glass fibres (aspect ratio $=10$ ), which formed extra air voids and caused the 238 premature failure. However, the reduction in the compressive strength for GFR-RPC was only $23910 \%$, which is less than the reduction of the compressive strength ( $25 \%$ reduction) reported for the 240 addition of polypropylene fibres in RPC in Canbaz [15]. The compressive strength of the HFR241 RPC was only 5.5\% lower than that of NF-RPC. The lower reduction in the compressive strength 242 of the HFR-RPC compared to that of GFR-RPC was due to the presence of the steel fibre in the 243 HFR-RPC. The steel fibre in HFR-RPC was $60 \%$ of the total volume of the fibres. This percentage 244 of steel fibres decreased the reduction in the compressive strength of the HFR-RPC.

245 Typical failure modes for the NF-RPC and FR-RPC investigated in this study under axial 246 compressive load are shown in Fig. 8. The failure of the NF-RPC was explosive with a loud sound.

247 The failure of the SFR-RPC, HFR-RPC and HFR-RPC was ductile with vertical cracks along the 248 specimens. 
250 Figure 9 shows typical axial load-axial deformation behaviour for the NF-RPC and FR-RPC. The

251 axial load-axial deformation behaviour of NF-RPC under uniaxial compression was linear up to

252 failure and all the specimens failed suddenly in an explosive manner at the peak axial load. The

253 addition of steel fibres, glass fibres and hybrid fibres prevented the sudden failure. The SFR-RPC

254 showed the most ductile behaviour compared to the GFR-RPC and HFR-RPC. The axial load-

255 axial deformation behaviour of SFR-RPC exhibited significant deformation after the maximum

256 axial load. Afterwards, the axial load of the SFR-RPC dropped and decreased steadily with

257 increasing deformation (softening response). The softening response dominated the axial load-

258 axial deformation behaviour of SFR-RPC up to the end of the test. The steel fibres contributed in

259 the ductile response of the SFR-RPC by extending the post-peak branch of the axial load-axial

260 deformation behaviour. It is well known that steel fibres arrest the propagation of cracks and delay

261 the onset of cracks in the concrete [31, 32]. The GFR-RPC and HFR-RPC specimens failed with

262 a significant drop in the axial load after the maximum axial load. However, the drop in the axial

263 load of the HFR-RPC followed by a decrease in the axial load with increasing axial deformation

264 up to the end of the test.

265

266 Figure 10 shows typical stress-strain behaviour for the NF-RPC and FR-RPC. The NF-RPC had 267 an average modulus of elasticity of $39 \mathrm{GPa}$. The average modulus of elasticity of SFR-RPC was $26840 \mathrm{GPa}$ and the average modulus of elasticity of HFR-RPC was $39 \mathrm{GPa}$. It is noted that steel and 269 hybrid (steel+glass) fibres used in this study had a marginal effect on the modulus of elasticity.

270 The average modulus of elasticity of GFR-RPC was 37 GPa. The lower modulus of elasticity for 
271 GFR-RPC compared to that of NF-RPC was attributed to the lower compressive strength of GFR272 RPC.

273

$274 \quad 3.3$ Indirect tensile strength of NF-RPC and FR-RPC

275 The average indirect tensile strength increased by the addition of steel and hybrid fibres from 7.6 276 MPa for NF-RPC to 9.9 MPa for SFR-RPC and 9.1 MPa for HFR-RPC (Table 2). The average 277 indirect tensile strength of GFR-RPC decreased compared to that of NF-RPC. The average indirect 278 tensile strength of GFR-RPC was found to be 5.7 MPa (Table 2). The lower indirect tensile strength 279 for GFR-RPC compared to that of NF-RPC could be explained by the failure type of fibre 280 reinforced concrete composite. Failure of fibre reinforced concrete composite occurred by either 281 the slippage or breaking of fibres based on the generated bond between the matrix material and 282 fibres [33]. In this study, the tensile failure can be associated with the slippage of fibres due to the 283 weak bond of the glass fibres with RPC matrix. This was probably due to the insufficient chemical 284 treatment of fibre surface, which was required to make the surface texture structurally suitable to 285 resist the high tensile stresses within the RPC matrix. Typical failure modes for the SFR-RPC, 286 GFR-RPC and HFR-RPC under splitting tensile test are shown in Fig. 11.

288 3.4 Direct shear strength of NF-RPC and FR-RPC

289 The direct shear test was conducted with some modifications of the recommendations in JSCE 290 SF6-1999 [29]. Two notches around the test specimens were formed to induce double shear failure. 291 However, all the RPC test specimens failed under direct shear load in one side only. This is 292 probably because the specimens were not restrained at the supports. Hence, the shear strength was 293 calculated according to Eq. (3), considering single shear failure. 


$$
\tau=\frac{1000 P}{B H}
$$

295 where, $\tau$ = shear strength (MPa), $P=$ maximum applied load $(\mathrm{kN}), B=$ effective width of specimen 296 (mm) and $\mathrm{H}=$ effective height of specimen (mm).

297

298 Some of the shear failure modes are shown in Fig. 12. The test observations revealed that the single 299 shear failure of NF-RPC was typical and sudden at the maximum load and identical to the failure 300 of SFR-RPC, HFR-RPC and GFR-RPC.

302 A significant improvement in the direct shear strength of NF-RPC occurred by the addition of the 303 fibres. The average direct shear strength increased clearly from $10 \mathrm{MPa}$ for NF-RPC to $25 \mathrm{MPa}$ 304 for SFR-RPC, 16 MPa for GFR-RPC and 22 MPa for HFR-RPC (Table 2). Maroliya [34] also 305 found that the shear strength of RPC increased with the addition of steel fibres. Boulekbache et al. 306 [35] reported that the addition of steel fibres increased the direct shear strength of both normal and 307 high strength concrete. Although RPC had no coarse aggregate, the direct shear strength of the 308 RPC increased with the addition of steel fibres.

310 Based on the results of this study, it was observed that SFR-RPC exhibited superior performance 311 compared to NF-RPC, GFR-RPC and HFR-RPC. In particular, SFR-RPC attained higher 312 compressive strength, modulus of elasticity, splitting tensile strength as well as shear strength than 313 NF-RPC, GFR-RPC and HFR-RPC. However, this study demonstrated that FR-RPC could be 314 produced by the addition of glass or steel-glass hybrid fibres. The GFR-RPC and HFR-RPC can 
315 be considered as alternatives of SFR-RPC when the use of only steel fibres in the RPC mix is not

316 desirable (e.g., structural RPC members exposed to corrosive environment). This study also

317 showed that the addition of fibres (steel, glass and steel-glass) in the RPC matrix could increase

318 the shear strength significantly.

\section{4. Conclusions}

320 An experimental program was conducted to investigate the influence of steel, glass and steel-glass

321 hybrid fibres on the compressive strength, modulus of elasticity, indirect tensile strength and shear

322 strength of RPC. Based on the experimental results of this study, the following conclusions can be

323 drawn.

324 1. The ratio of the compressive strength at 7 days to the compressive strengths at 28 days for NF-

325 RPC was $88 \%$. The ratio of compressive strength at 56 days to the compressive strengths at 28

326 days for NF-RPC was $113 \%$. The ratio of compressive strength at 7 days to the compressive

327 strengths at 28 days for NF-RPC was found to be about 33\% higher than that of normal strength

328 concrete. The ratio of compressive strength at 56 days to the compressive strengths at 28 days

329 for NF-RPC was found to be similar to that of normal strength concrete. The addition of $1.5 \%$

330 by volume of steel fibres in the RPC increased the average compressive strength by 6.6\%, while

331 the addition of $1.5 \%$ by volume of the glass and the hybrid (steel plus glass) fibres in the RPC

332 decreased the average compressive strength by $10 \%$ and $5.5 \%$, respectively, compared to the 333 average compressive strength of NF-RPC.

334 2. The average modulus of elasticity of NF-RPC was 39 GPa. The SFR-RPC achieved average 335 modulus of elasticity marginally higher than that of NF-RPC, and HFR-RPC achieved average 336 modulus of elasticity equals to that of NF-RPC. In contrast, the average modulus of elasticity 337 for GFR-RPC was 5\% lower than the modulus of elasticity for NF-RPC. 
3. Average splitting tensile strength of NF-RPC increased by about $30 \%$ and $20 \%$ with the addition of the steel and hybrid steel-glass fibres, respectively. However, the average splitting

340 tensile strength of NF-RPC decreased by 25\% after the addition of the glass fibres.

341 4. The average shear strength of RPC under direct shear demonstrated a significant improvement

342 with the addition of the fibres (steel, glass and steel-glass fibres). The SFR-RPC achieved 343 average shear strength about $150 \%$ higher than that of NF-RPC. Also, the average shear 344 strengths of GFR-RPC and HFR-RPC were about $60 \%$ and $120 \%$, respectively, higher than that 345 of NF-RPC.

\section{Acknowledgement}

347 The authors acknowledge the University of Wollongong, Australia, for the financial support to this 348 experimental study. The authors acknowledge, Australasian (iron \& steel) Slag Association for the 349 free supply of the silica fume. The first author would like to acknowledge the Iraqi government 350 for the full financial support to his PhD study. Special thanks to all technical staff in the Structural 351 Engineering laboratories at the University of Wollongong, Australia.

\section{References}

354 1. Richard P, Cheyrezy M. Composition of reactive powder concretes. Cement and concrete 355 research, 1995, 25(7): 1501-1511.

356 2. Lee M-G, Wang Y-C, Chiu C-T. A preliminary study of reactive powder concrete as a new 357 repair material. Construction and Building Materials, 2007, 21(1): 182-189. 
358 3. Yunsheng Z, Wei S, Sifeng L, Chujie J, Jianzhong L. Preparation of C200 green reactive powder 359 concrete and its static-dynamic behaviors. Cement and Concrete Composites, 2008, 30(9): 831360838.

361 4. Chang T, Chen B, Wang J, Wu C, eds. Performance of Reactive Powder Concrete (RPC) with 362 different curing conditions and its retrofitting effects on concrete member. London: Taylor \& 363 Francis Group, 2009, 1203-1208.

364 5. Malik A R, Foster S J. Carbon fibre-reinforced polymer confined reactive powder concrete 365 columns-experimental investigation. ACI Structural Journal, 2010, 107(03): 263-271.

366 6. Lee N P, Chisholm D H. Reactive Powder Concrete. New Zealand, Study Report no. SR146, $3672005,1-29$.

368 7. Tam C M, Ng K M, Tam V W Y. Optimal conditions for producing reactive powder concrete. 369 Magazine of Concrete Research, 2010, 62(10): 701-716.

370 8. Hiremath P N, Yaragal S C. Effect of different curing regimes and durations on early strength 371 development of reactive powder concrete. Construction and Building Materials, 2017, 154(1): 7237287.

373 9. Al-Tikrite A, Hadi M N S. Mechanical properties of reactive powder concrete containing 374 industrial and waste steel fibres at different ratios under compression. Construction and Building 375 Materials, 2017, 154(1): 1024-1034.

376 10. Liu C-T, Huang J-S. Fire performance of highly flowable reactive powder concrete. 377 Construction and Building Materials, 2009, 23(5): 2072-2079.

378 11. Ahmad S, Zubair A, Maslehuddin M. Effect of key mixture parameters on flow and mechanical 379 properties of reactive powder concrete. Construction and Building Materials, 2015 99(1): 73-81. 
12. Ju Y, Jia Y, Liu H, Chen J. Mesomechanism of steel fibre reinforcement and toughening of 381 reactive powder concrete. Science in China Series E: Technological Sciences, 2007, 50(6): 815382832.

383 13. Shaheen E, Shrive N. Optimization of mechanical properties and durability of reactive powder 384 concrete. ACI Materials Journal, 2006, 103(6): 444-451.

385 14. Sanchayan S, Foster S J. High temperature behaviour of hybrid steel-PVA fibre reinforced 386 reactive powder concrete. Materials and Structures, 2015, 48(1): 1-15.

387 15. Canbaz M. The effect of high temperature on reactive powder concrete. Construction and 388 Building Materials, 2014, 70(1): 508-513.

389 16. Ferreira J P J G, Branco F A B. The Use of Glass Fibre Reinforced Concrete as a Structural 390 Material. Experimental Techniques, 2007, 31(3): 64-73.

391 17. G R C A. Specifiers Guide to Glass Reinforced Concrete. Glass Reinforced Concrete 392 Association, UK, 2012, 1-4.

393 18. AS 3972. General purpose and blended cements. Australian Standards, Sydney, NSW, 2010.

394 19. SIMCOA operations pty. Itd., Micro silica material safety data sheet, 395 http://www.simcoa.com.au/, 2018 (accessed 06.04.18).

396 20. Australasian (iron \& steel) Slag Association (ASA), Wollongong, NSW, Australia. 397 http://www.asa-inc.org.au/, 2018 (accessed 06.04.18).

398 21. Sika Australia, Sika Viscocrete PC HRF-2 High Range Water Reducer-Material safety data 399 sheet. http:// www.Sika.com.au/, 2018 (accessed 06.04.18).

400 22. Ganzhou Daye Metallic Fibres Co., Ltd., Micro steel fibre WSF0213 III specifications. 401 http://www.gzdymf.com/, 2018 (accessed 06.04.18). 
402 23. Nippon Electric Glass Co., Ltd., (NEG), High Integrity chopped strand alkali resistant glass

403 fibre. http://www.neg.co.jp/EN/common/image/header_logo.gif, 2018 (accessed 06.04.18).

404 24. ASTM C230/C230M-14. Standard Specification for Flow Table for use in Tests of Hydraulic

405 Cement. American Society for Testing and Materials, West Conshohocken, PA, United States, 4062014.

407 25. Malik A R, Foster S J. Behaviour of reactive powder concrete columns without steel ties.

408 Journal of advanced concrete technology, 2008, 6(2): 377-386.

409 26. AS 1012.9. Compressive strength tests - concrete, mortar and grout specimen. Australian

410 Standards, Sydney, NSW, 2014.

411 27. AS 1012.17. Methods of testing concrete: Determination of the static chord modulus of 412 elasticity and Poisson's ratio of concrete specimens. Australian Standards, Sydney, NSW, 2014.

413 28. AS 1012.10. Determination of indirect tensile strength of concrete cylinders. Australian 414 Standards, Sydney, NSW, 2014.

415 29. JS SF6. Method of test for shear strength of steel fibre reinforced concrete. Japan Society of 416 Civil Engineers (JSCE), Tokyo, Japan, 1999.

417 30. Anderson R, Dewar J. Manual of ready-mixed concrete. 3thed. London: CRC Press, 2003.

418 [31] Hadi MN. Behaviour of eccentric loading of FRP confined fibre steel reinforced concrete 419 columns. Construction and Building Materials, 2009, 23: 1102-1108.

420 [32] Ou Y-C, Tsai M-S, Liu K-Y, Chang K-C. Compressive behavior of steel-fiber-reinforced 421 concrete with a high reinforcing index. Journal of Materials in Civil Engineering, 2011, 24: 207422215.

423 33. Mehta P K, Monteiro P J M. Concrete: Microstructure, Properties, and Materials. $4^{\text {th }}$ edn. New 424 York: McGraw-Hill Education, 2014. 
425 34. Maroliya M. Behavior of reactive powder concrete in direct shear. IOSR Journal of 426 Engineering (IOSRJEN), 2012, 2(9): 76-79.

427 35. Boulekbache B., Hamrat M., Chemrouk M., Amziane S. Influence of yield stress and 428 compressive strength on direct shear behaviour of steel fibre-reinforced concrete. Construction and 429 Building Materials, 2012, 27(1): 6-14.

430

431

432

433

434

435

436

437

438

439

440

441

442

443

444

445 
$447 \quad$ List of Tables

448 Table 1 Properties of steel and glass fibres

449 Table 2 Experimental mechanical properties of NF-RPC and FR-RPC at 28 days * 450

451

452

453

454

455

456

457

458

459

460

461

462

463

464

465 


\section{$467 \quad$ List of Figures}

468 Fig. 1 Steel and glass fibres

469 Fig. 2 Flow table test

470 Fig. 3 Test setup for axial load-axial deformation behaviour

$471 \quad$ Fig. 4 Test setup for splitting tensile strength

472 Fig. 5 Schematic of the direct shear test

$473 \quad$ Fig. 6 Test setup for shear strength

474 Fig. 7 Age versus compressive strength for NF-RPC

475 Fig. 8 Typical failure modes of NF-RPC and FR-RPC under compressive axial load

476 Fig. 9 Typical axial load-axial deformation behaviour of NF-RPC and FR-RPC

477 Fig. 10 Typical stress-strain behaviour of NF-RPC and FR-RPC

478 Fig. 11 Typical failure modes of SFR-RPC, GFR-RPC and HFR-RPC under splitting tensile test

479 Fig. 12 Typical failure modes of NF-RPC and FR-RPC under direct shear 
490 Table 1 Properties of steel and glass fibres

\begin{tabular}{lll}
\hline Property & $\begin{array}{l}\text { Steel fibre } \\
{[22]}\end{array}$ & Glass fibre [23] \\
\hline Length (mm) & 13 & 13 \\
Diameter (mm) & 0.2 & 1.3 \\
Aspect ratio (length/diameter) & 65 & 10 \\
Density (g/cm $\left.{ }^{3}\right)$ & 7.8 & 2.8 \\
Tensile Strength (MPa) & 2500 & 1500 \\
\hline
\end{tabular}

491

492

493

494

495

496

497

498

499

500

501

502

503

504

505 
507 Table 2 Experimental mechanical properties of NF-RPC and FR-RPC at 28 days *

\begin{tabular}{llllll}
\hline $\begin{array}{l}\text { Mix } \\
\text { notation }\end{array}$ & $\begin{array}{l}\text { Compressive } \\
\text { strength (MPa) }\end{array}$ & $\begin{array}{l}\text { Average } \\
\text { flow } \\
\text { diameter } \\
(\mathrm{mm})\end{array}$ & $\begin{array}{l}\text { Modulus of } \\
\text { elasticity, } \\
(\mathrm{GPa})\end{array}$ & $\begin{array}{l}\text { Indirect } \\
\text { tensile } \\
\text { strength, } \\
(\mathrm{MPa})\end{array}$ & $\begin{array}{l}\text { Shear } \\
\text { strength, } \tau \\
(\mathrm{MPa})\end{array}$ \\
\hline NF-RPC & 90 & 200 & 39 & 7.6 & 10 \\
\hline St. Dev. & 1.52 & - & 2.12 & 0.23 & 1.41 \\
SFR-RPC & 96 & 190 & 40 & 9.9 & 25 \\
St. Dev. & 2.51 & - & 2.83 & 0.26 & 3.05 \\
GFR-RPC & 81 & 180 & 37 & 5.7 & 16 \\
St. Dev. & 2.64 & - & 2.52 & 0.32 & 2.30 \\
HFR-RPC & 85 & 185 & 39 & 9.1 & 22 \\
St. Dev. & 2.46 & - & 2.51 & 0.37 & 2.64 \\
\hline
\end{tabular}

$508 *$ Each result is an average of three tested specimens

509

510

511 

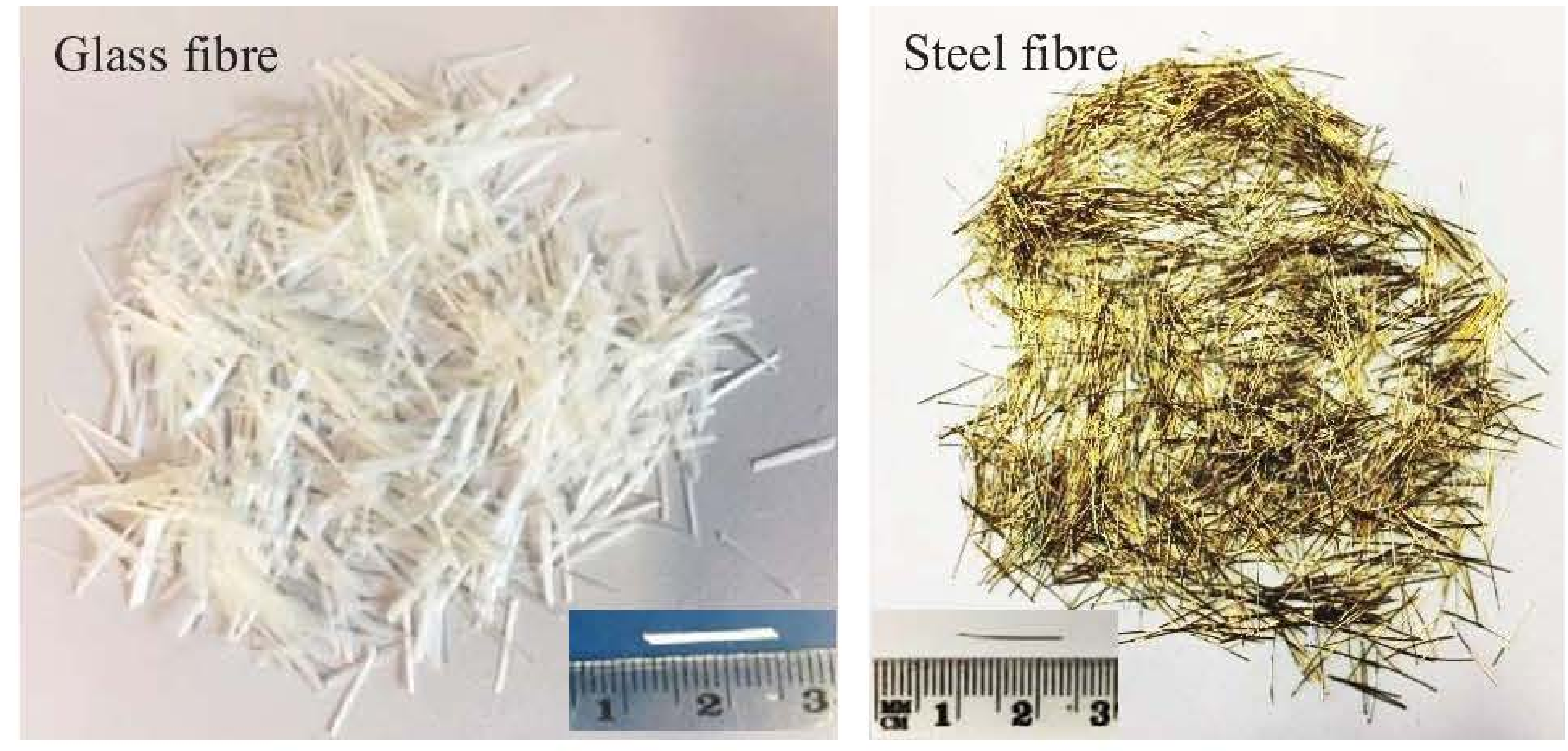

Fig. 1 Steel and glass fibres 


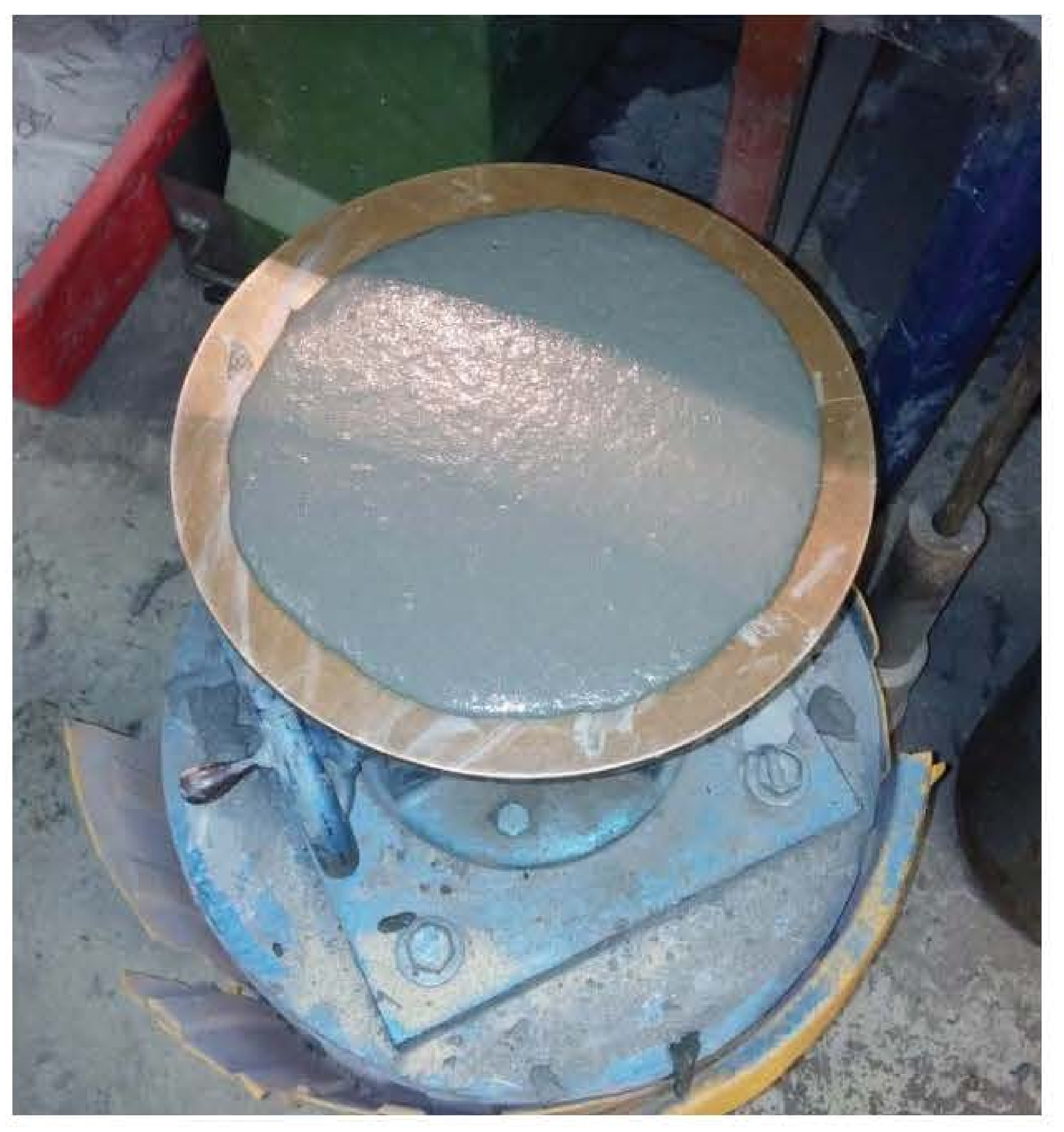

Fig. 2 Flow table test 


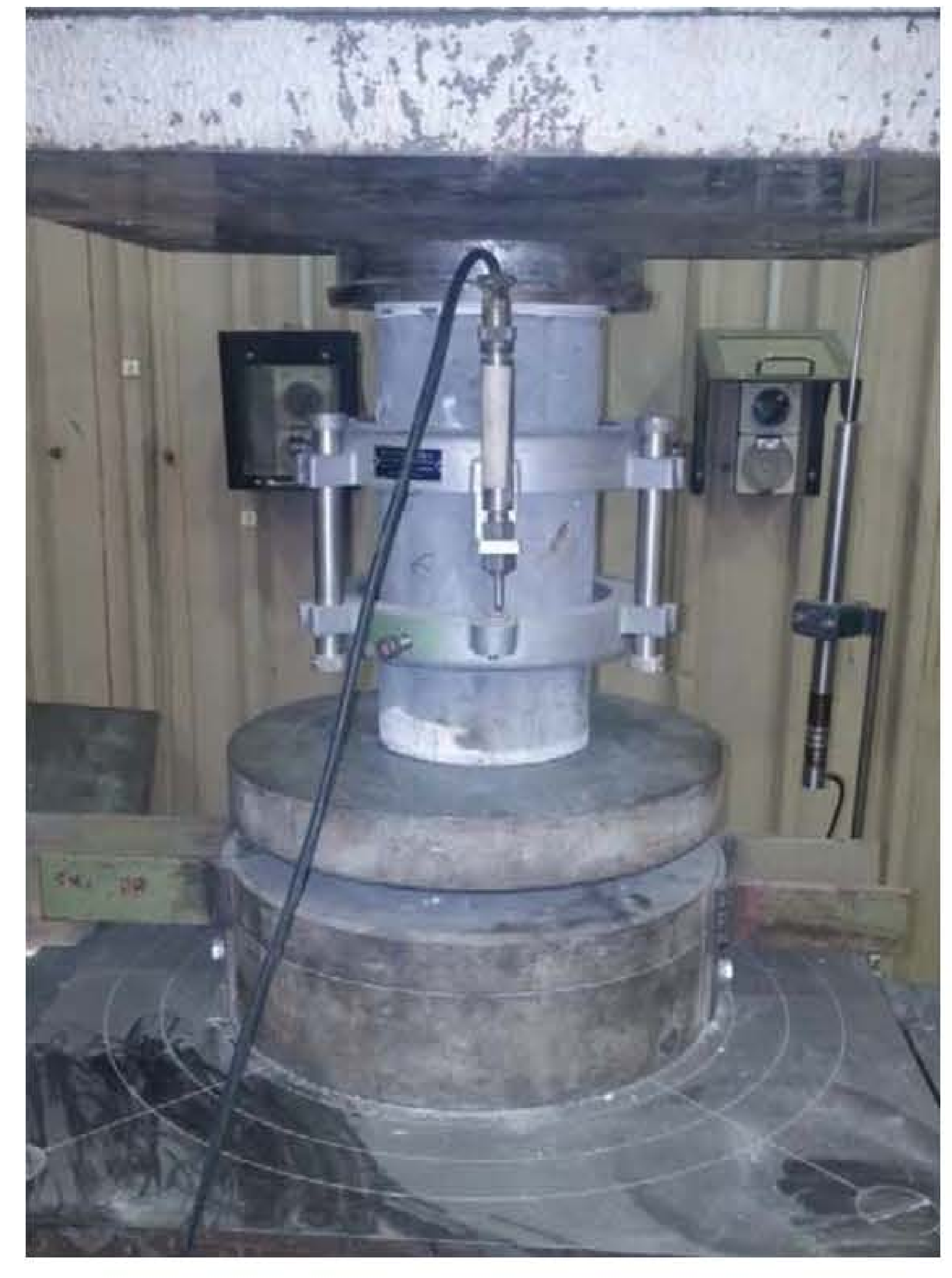

Fig. 3 Test setup for axial load-axial deformation behaviour 


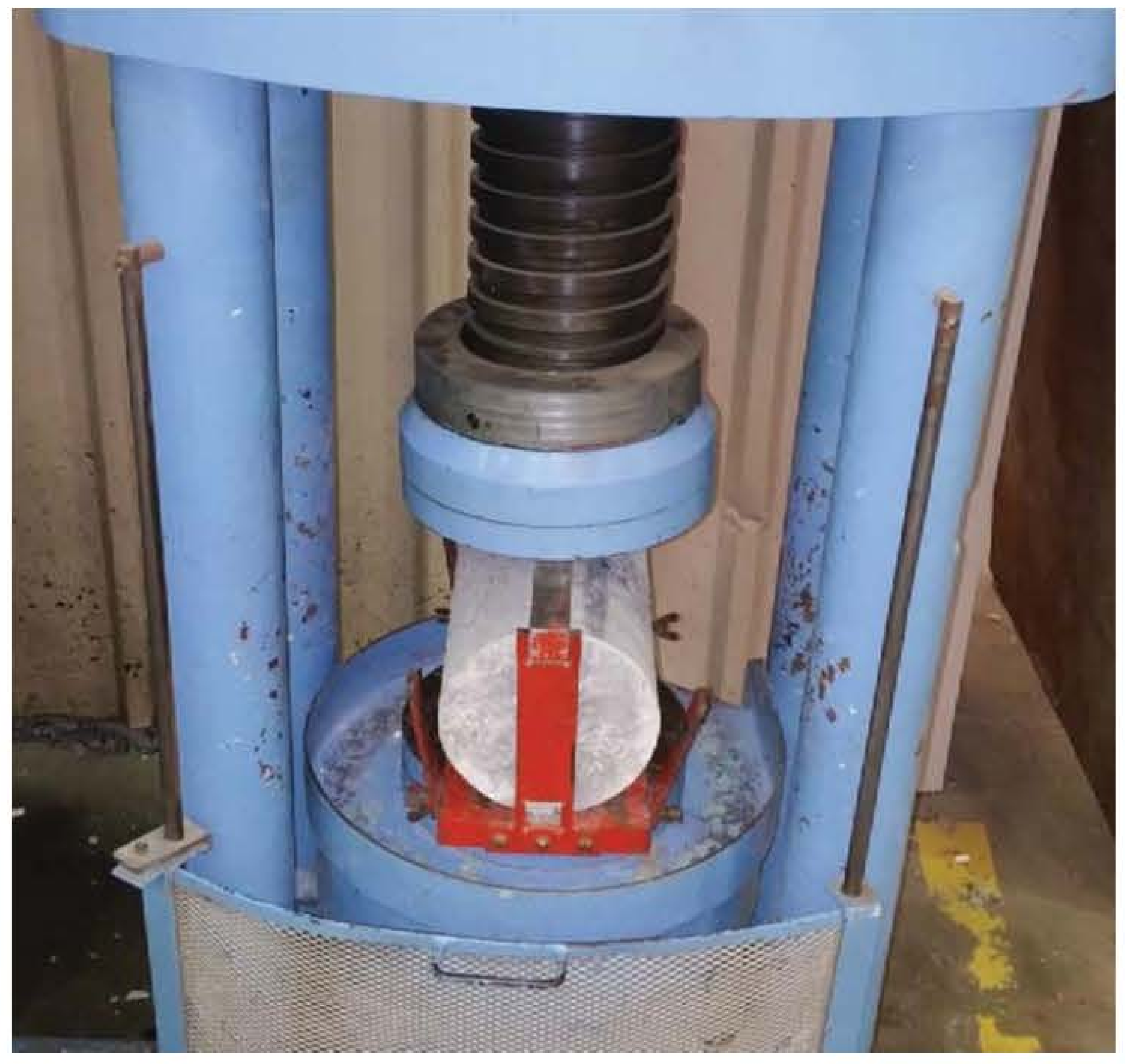

Fig. 4 Test setup for splitting tensile strength 


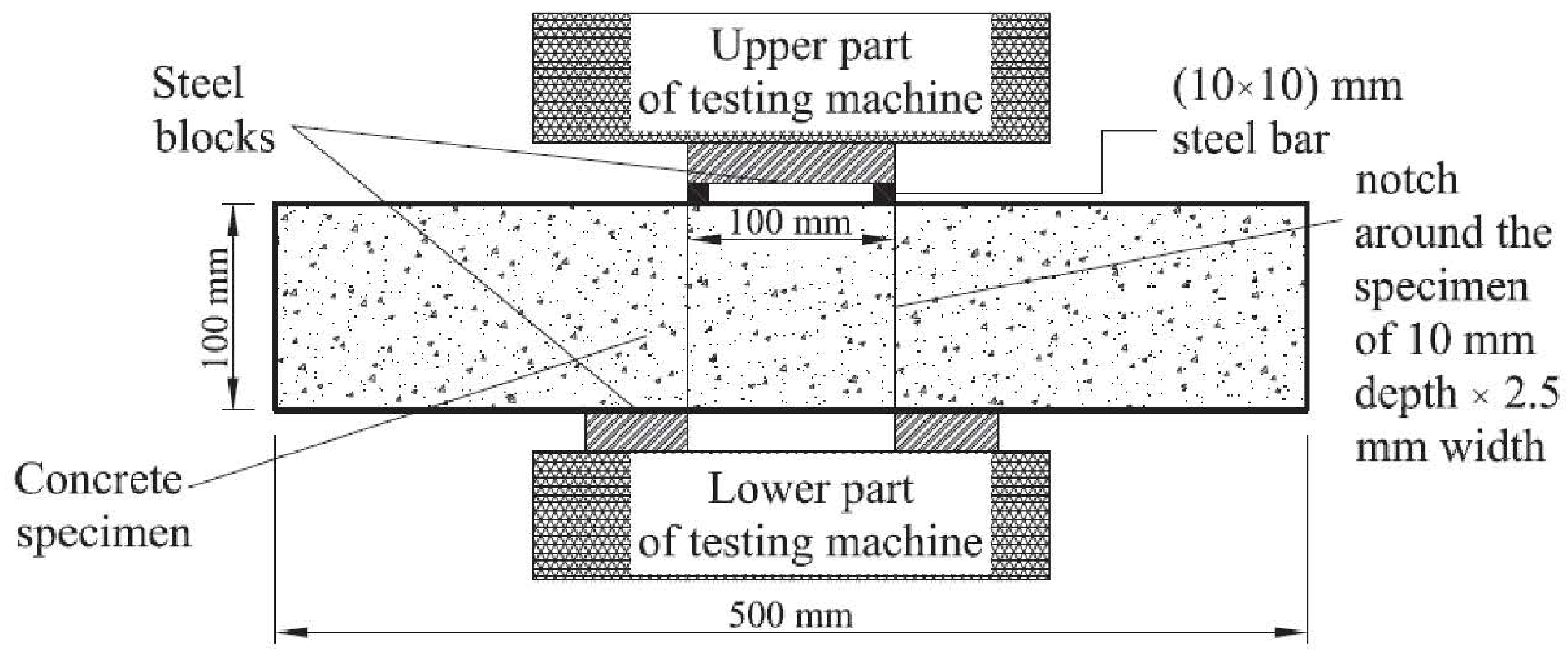

Fig. 5 Schematic of the direct shear test 


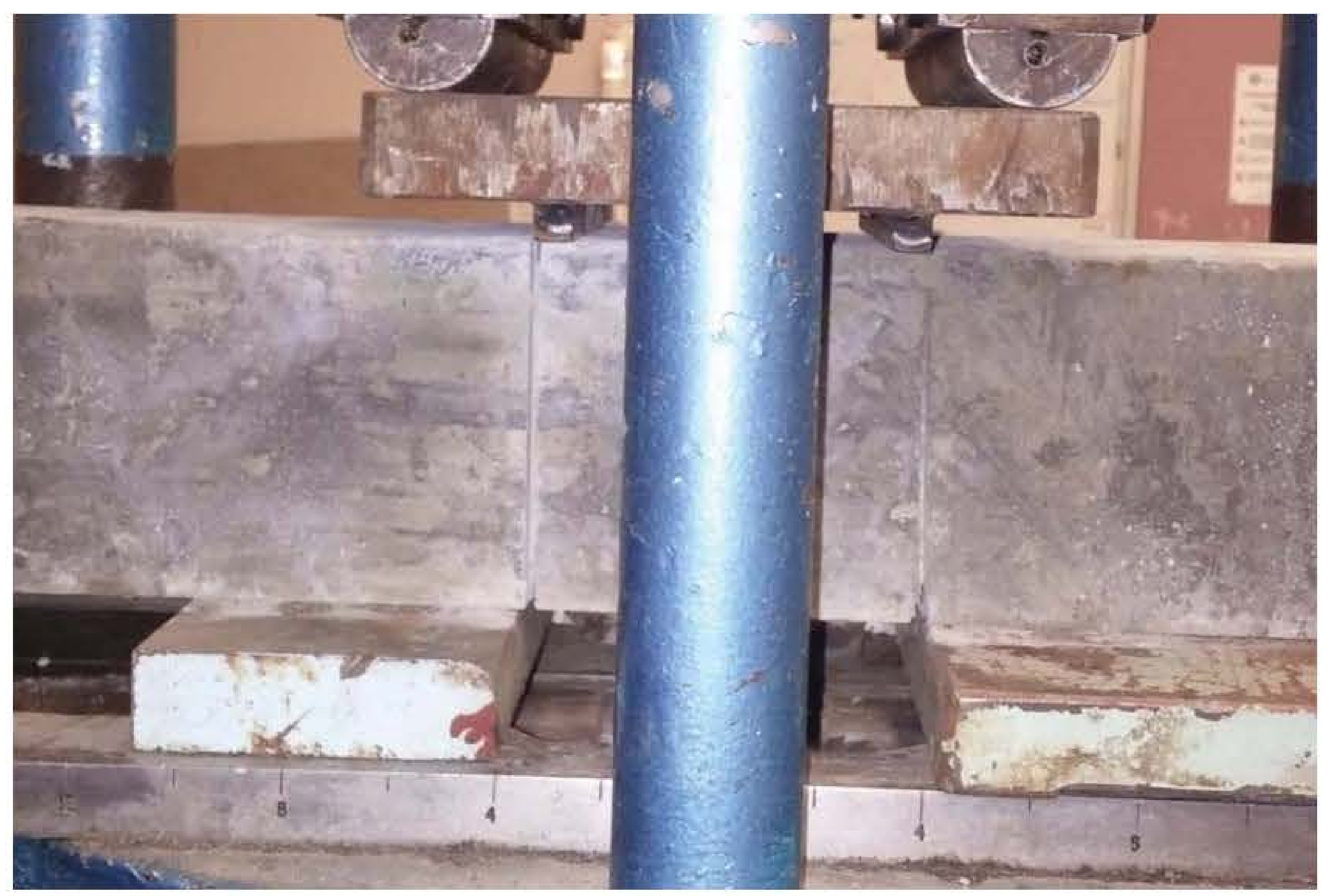

Fig. 6 Test setup for shear strength 


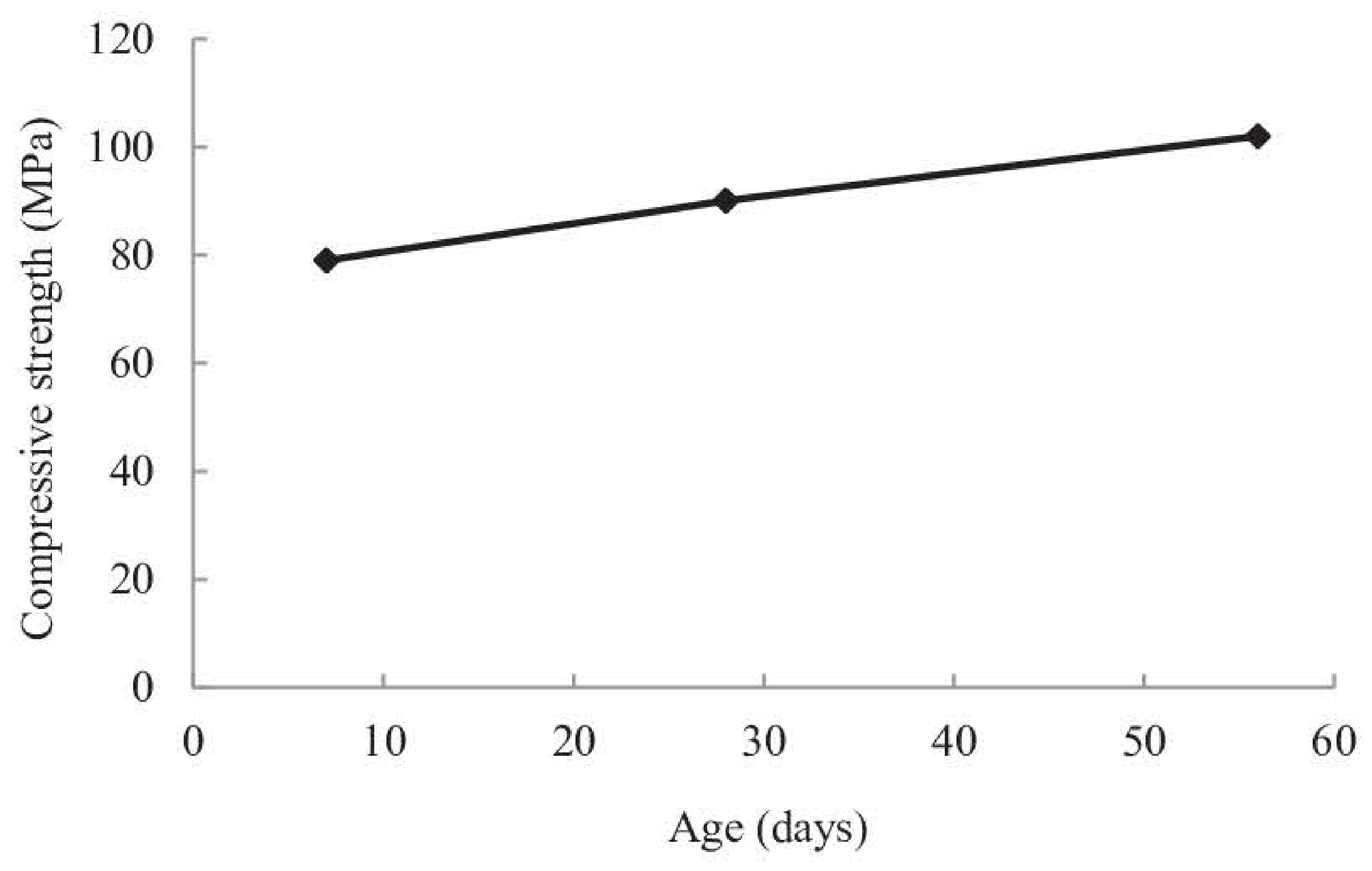

Fig. 7 Age versus compressive strength for NF-RPC 


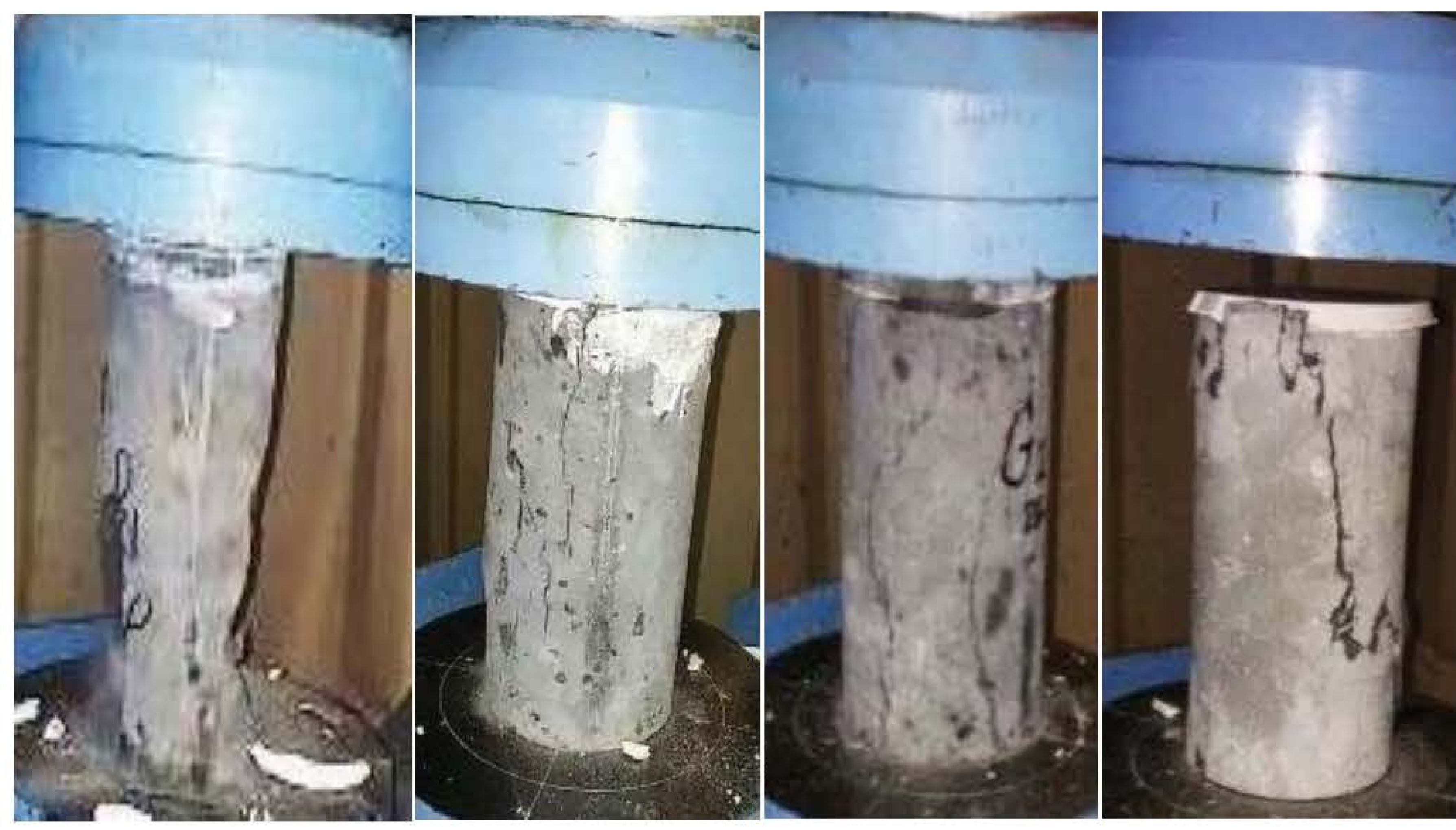

NF-RPC SFR-RPC $\quad$ GFR-RPC $\quad$ HFR-RPC

Fig. 8 Typical failure modes of NF-RPC and FR-RPC under compressive axial load 


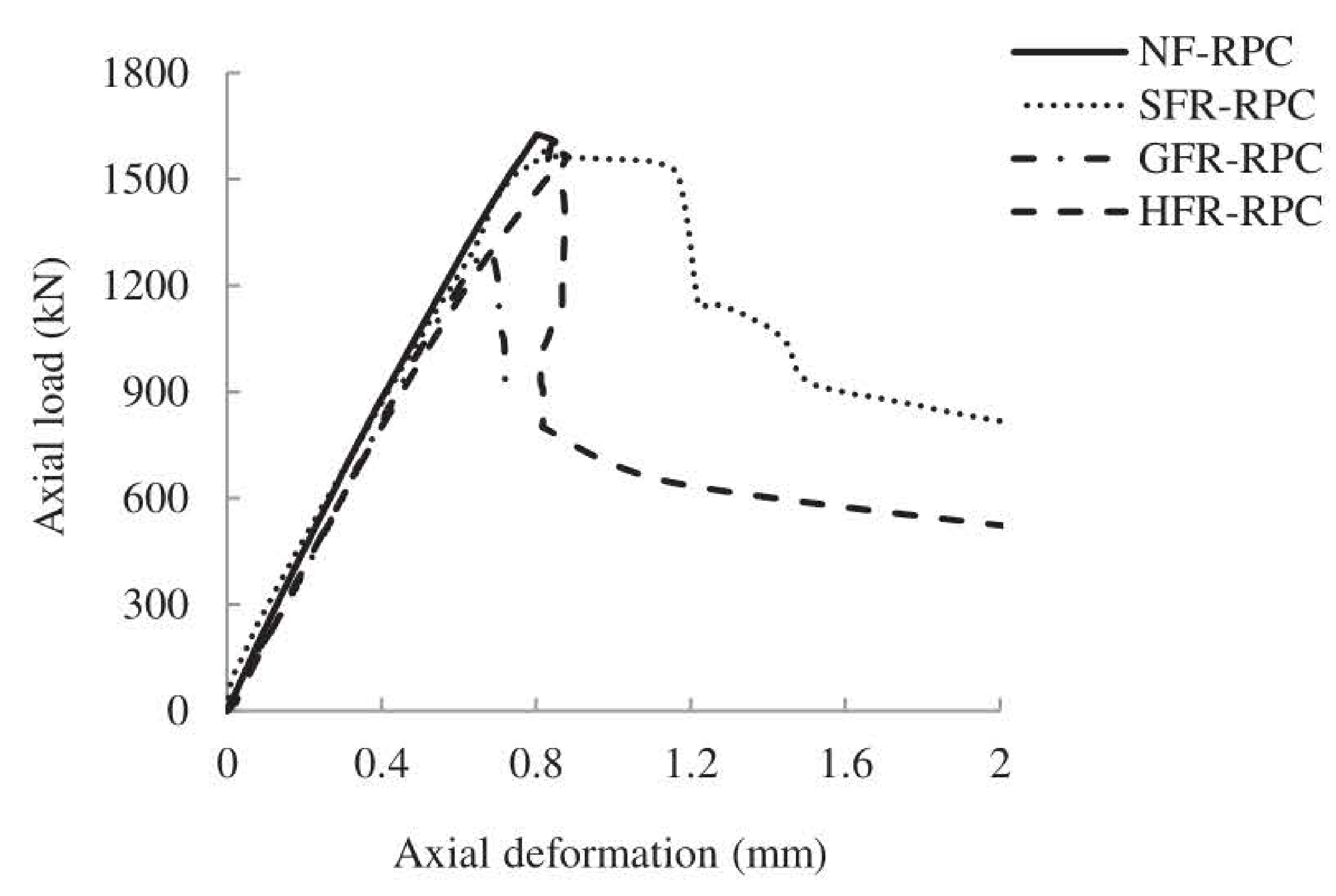

Fig. 9 Typical axial load-axial deformation behaviour of NF-RPC and FR-RPC 


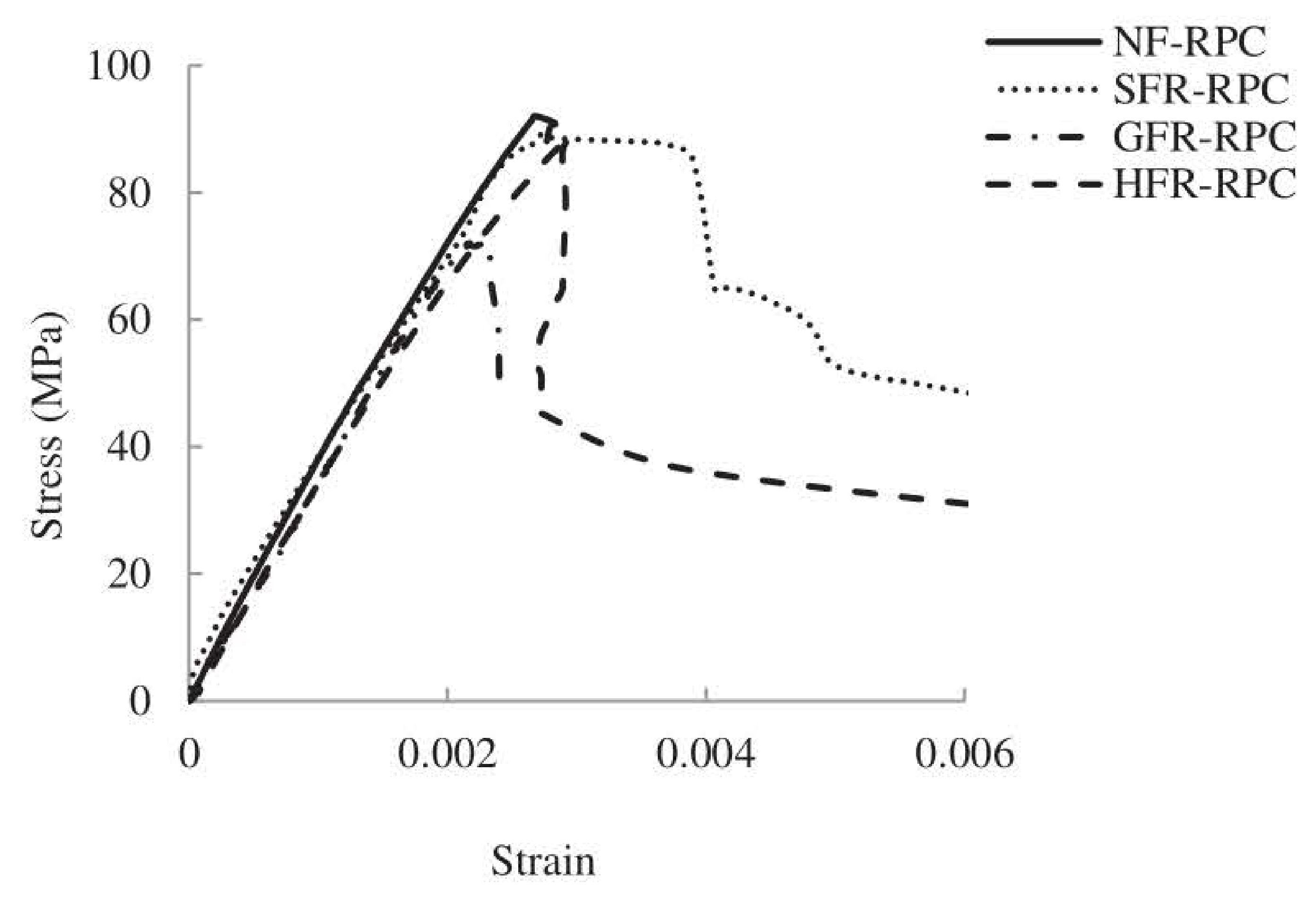

Fig. 10 Typical stress-strain behaviour of NF-RPC and FR-RPC 

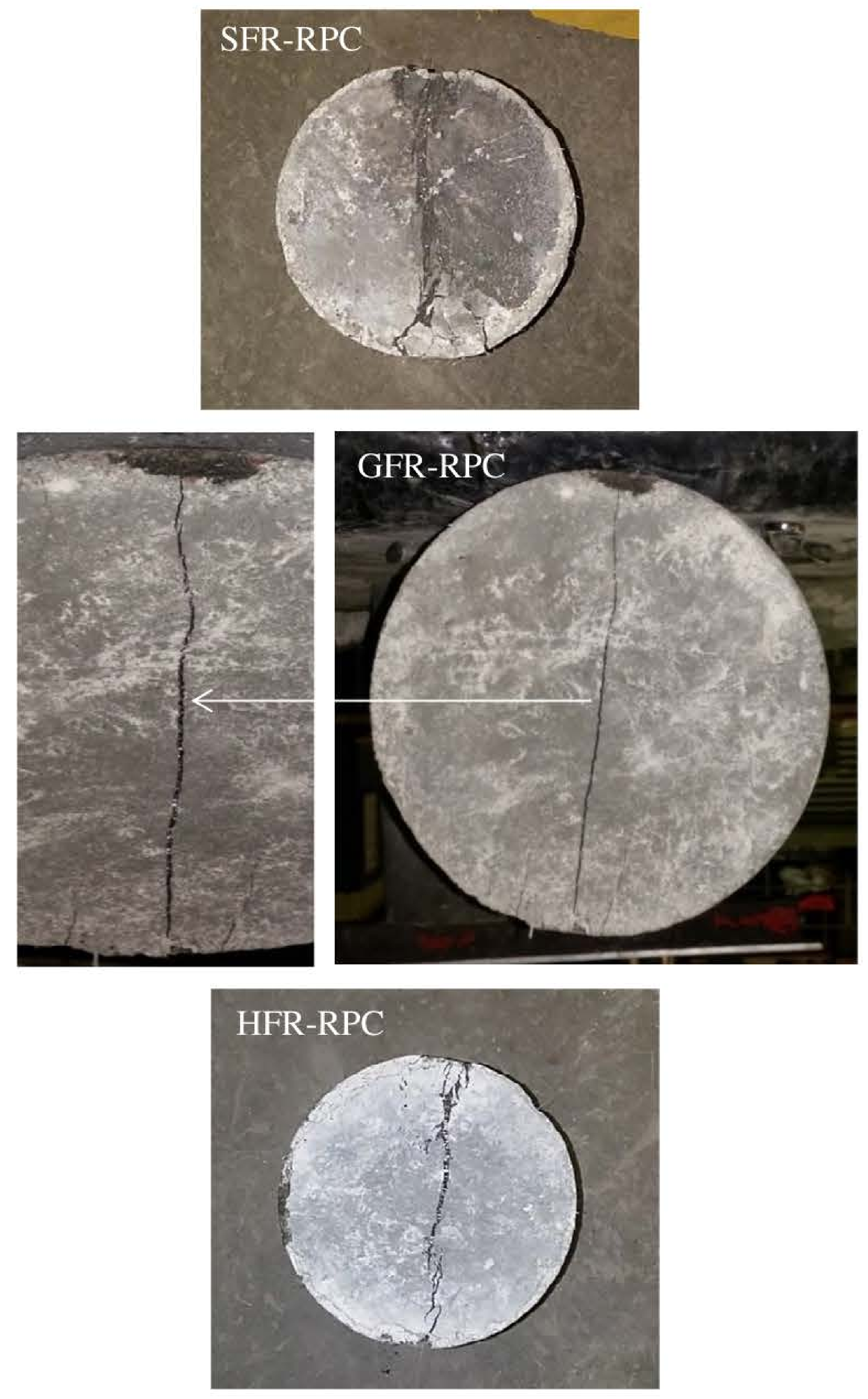

Fig. 11 Typical failure modes of SFR-RPC, GFR-RPC and HFR-RPC under splitting tensile test 


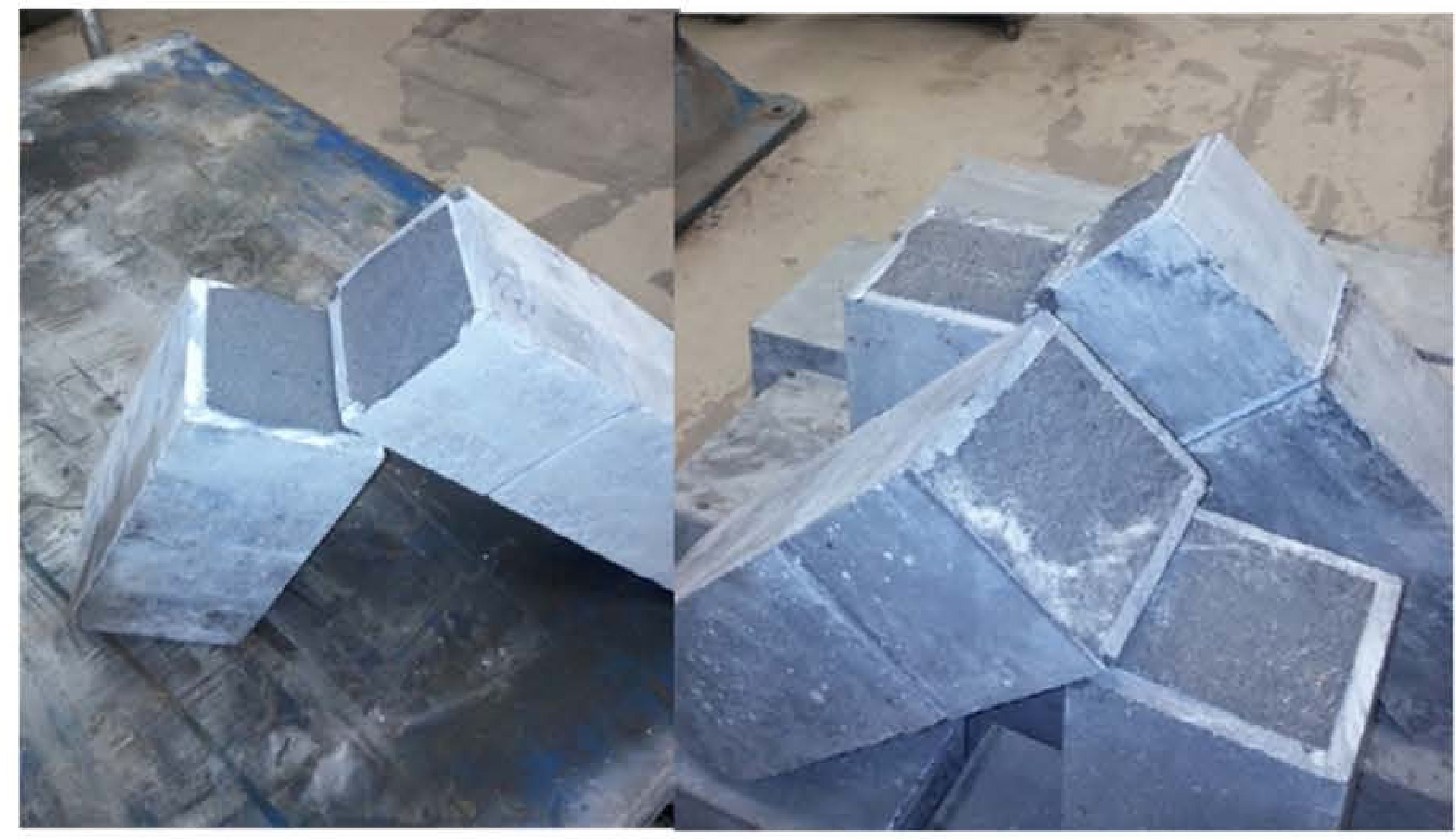

Fig. 12 Typical failure modes of NF-RPC and FR-RPC under direct shear 